\title{
Strategies to Improve Vaccine Efficacy against Tuberculosis by Targeting Innate Immunity
}

\author{
Ulrich E. Schaible ${ }^{1,2}$, Lara Linnemann ${ }^{1}$, Natalja Redinger ${ }^{1}$, Emmanuel C. Patin ${ }^{1,3}$ \\ and Tobias Dallenga ${ }^{1,2 *}$
}

${ }^{1}$ Cellular Microbiology, Priority Program Infections, Research Center Borstel, Borstel, Germany, ${ }^{2}$ Thematic Translation Unit Tuberculosis, German Center for Infection Research, Research Center Borstel, Borstel, Germany, ${ }^{3}$ Retroviral Immunology, The Francis Crick Institute, London, United Kingdom

The global tuberculosis epidemic is the most common cause of death after infectious disease worldwide. Increasing numbers of infections with multi- and extensively drug-resistant variants of the Mycobacterium tuberculosis complex, resistant even to newly discovered and last resort antibiotics, highlight the urgent need for an efficient vaccine. The protective efficacy to pulmonary tuberculosis in adults of the only currently available vaccine, $M$. bovis BCG, is unsatisfactory and geographically diverse. More importantly, recent clinical studies on new vaccine candidates did not prove to be better than BCG, yet. Here, we propose and discuss novel strategies to improve efficacy of existing anti-tuberculosis vaccines. Modulation of innate immune responses upon vaccination already provided promising results in animal models of tuberculosis. For instance, neutrophils have been shown to influence vaccine efficacy, both, positively and negatively, and stimulate specific antibody secretion. Modulating immune regulatory properties after vaccination such as induction of different types of innate immune cell death, myeloid-derived suppressor or regulatory T cells, production of anti-inflammatory cytokines such as IL-10 may have beneficial effects on protection efficacy. Incorporation of lipid antigens presented via CD1 molecules to T cells have been discussed as a way to enhance vaccine efficacy. Finally, concepts of dendritic cell-based immunotherapies or training the innate immune memory may be exploitable for future vaccination strategies against tuberculosis. In this review, we put a spotlight on host immune networks as potential targets to boost protection by old and new tuberculosis vaccines.

\footnotetext{
Keywords: tuberculosis, vaccine, Mycobacterium tuberculosis, host-directed therapy, neutrophils, IL-10, CD1, cell death
}

\section{INTRODUCTION}

With 1.8 million deaths worldwide, the World Health Organization listed tuberculosis among the top 10 causes of death in 2015 (1) and positioned tuberculosis to be the number one killer after infectious disease. Alarmingly high numbers of cases with multidrug- (MDR) and extensively drug-resistant (XDR) variants, prompted the G20 leaders to single out tuberculosis within the emerging problem of antibiotic resistance in their 2017 summit declaration. Nearly, half a million people were identified to be infected with MDR strains of Mycobacterium tuberculosis in 2016 but not even half of them were treated successfully (1). A number of XDR tuberculosis cases are even considered untreatable. Those patients have a survival rate of only $30 \%$ (1). These figures highlight the global tuberculosis health crisis and emphasize how urgently novel vaccines are needed. 
As of today, the widely used attenuated live vaccine $M$. bovis BCG provides only limited protection. It is effective against primary tuberculosis during childhood, which can lead to severe outcomes, including meningitis. However, the protective efficacy of BCG against pulmonary tuberculosis in adults is unsatisfactory and varies tremendously between geographical areas, concretely the greater the distance from the equator the higher the efficacy (2). Consequently, huge scientific and financial efforts have been made to design and develop novel vaccine types, hoping to enhance protective immunity against tuberculosis in adults. The aims are either to sterilely eliminate the mycobacteria or-at least-prevent forms of active disease, such as contagious pulmonary tuberculosis in order to limit transmission. Still, none of the novel vaccine candidates have replaced BCG. A booster vaccine candidate with just one mycobacterial antigen, MVA85A, which was promising in animal models, failed to enhance BCG-primed protection in a recent clinical study in South Africa (3). In this approach, the secreted mycobacterial mycosyl transferase Ag85A, involved in the synthesis of trehalose dimycolate, cell wall maintenance, and $M$. tuberculosis survival (4), was cloned into a recombinant strain of modified Vaccinia Ankara virus (5) to be used as booster vaccine following BCG priming. Despite induction of antigen-specific multifunctional Th1 and Th17 cells in infants that received MVA85A on top of BCG priming (3), 1,399 vaccinees were not better protected from tuberculosis than the placebo controls, raising the question, whether BCG-centric vaccine strategies that aim to elicit potent Th1 cell responses against dominant antigens are still the most promising approaches (6).

A different approach to improve vaccine efficacy is to modulate host immune networks concomitantly or upon vaccination, using old and new vaccines to boost protection. Immune system networks may be exploited to bias immune responses toward protective immunity against tuberculosis. Various host responses following vaccination have been described to interfere with establishment of protective immunity similar as it is seen after natural infection (7). In this review, we discuss novel approaches, which may improve anti-tuberculosis vaccination. These include targeting neutrophils as well as the type of phagocyte cell death, i.e., necroptosis vs. apoptosis during vaccination. We review CD1-binding lipids as antagonists for CD1-restricted $\mathrm{T}$ cell responses, which may interfere with proper vaccine-mediated immunity. Additionally, immunoregulatory cytokines such as IL-10 may also affect vaccine efficacy and, thus, are putative targets for vaccination-accompanying immunomodulation. Finally, based on promising results in immunotherapy of cancer, we will consider whether induction of immunogenic cell death has the potential to enhance $\mathrm{T}$ cell responses.

\section{NEUTROPHILS UPON VACCINATION: THE GOOD, THE BAD, OR THE NEUTRAL FOR VACCINE EFFICACY}

Neutrophils are associated with disease in patients with active tuberculosis and susceptible mouse strains developing necrotic granulomas similar to humans. These potent anti-microbial innate immune cells have been shown to represent the main cell population in bronchoalveolar lavage and sputum of patients with active pulmonary tuberculosis and they carry the main mycobacterial load (8). Berry et al. identified a blood mRNA profile, which was dominated by a neutrophil signature and allowed to discriminate between active tuberculosis patients, latently infected ones, and healthy controls (9). Moreover, neutrophil-rich lesions associated with necrotic caseous material were found in resected lungs of patients (10). Thus, active pulmonary tuberculosis is considered to be neutrophil-driven (11). Susceptible mouse models, mimicking the pathology of human tuberculosis, such as $\mathrm{C} 3 \mathrm{HeB} / \mathrm{FeJ}, \mathrm{DBA} / 2$, and I/St, show strong contribution of neutrophils to mycobacterial load, tissue destruction, pathology, and decreased survival rates (12-14). Importantly, not only in active $M$. tuberculosis infection but also after subcutaneous BCG vaccination, neutrophils rapidly enter the site of injection in large numbers (15). Neutrophil influx is also observed in response to vaccination using the synthetic trehalose dimycolate analog, trehalose-6,6-dibehenate (TDB), in a liposome formulation as adjuvant at the site of subcutaneous injection (Figure 1). Trehalose dibehenate was proposed as adjuvant to boost efficacy of subunit vaccines against tuberculosis (16). Neutrophils have also been shown to shuttle bacterial antigens to draining lymph nodes for T cell priming (17). However, contradictory roles for neutrophils regarding vaccine efficacy have been described.

Neutrophils have been shown to activate B cells leading to antibody secretion. After reprogramming by IL-10, among other signals, neutrophils entered the marginal zone of the spleen upon mucosal colonization by microbes in murine neonates (18). Here, the neutrophils exhibited a B cell-helper phenotype and induced immunoglobulin diversification and production by $\mathrm{T}$ cell-independent $\mathrm{B}$ cell activation. However, splenic B cell-helper neutrophils have not been detected in humans so far (19). Nagelkerke et al. identified a homogenous neutrophil population in human spleen that did not exhibit enhanced capabilities over blood neutrophils regarding co-stimulation of B cells and antibody production thereof. Classically, B cellmediated immunity was thought to contribute only little to protection against tuberculosis. However, more recent studies reveal the potential of specific antibodies to contribute to immune protection against $M$. tuberculosis infection as comprehensively reviewed elsewhere $(20,21)$. In another study, murine bone marrow-derived neutrophils have been shown to exhibit a neutrophil-dendritic cell hybrid phenotype when cultured with GM-CSF (22). Those cells showed both, typical neutrophil properties, like NET formation and cathelicidin-mediated bacterial killing as well as intrinsic abilities of dendritic cells, like expression of MHC class II and co-stimulatory molecules and IL-12 production. The cells were capable of antigen presentation to $\mathrm{T}$ cells. Therefore, shifting the neutrophil phenotype elicited by vaccination toward this unusual subtype, for example, by concomitant administration of rGM-CSF, may strengthen vaccine efficacy. This subtype of antigen-presenting neutrophil, named $\mathrm{N}_{\beta}$, was identified to migrate to the site of HIV infection in an NF-kB-dependent manner and activate specific $\mathrm{CD}^{+} \mathrm{T}$ cells (23). However, the function of $\mathrm{N}_{\beta}$ neutrophils in tuberculosis 


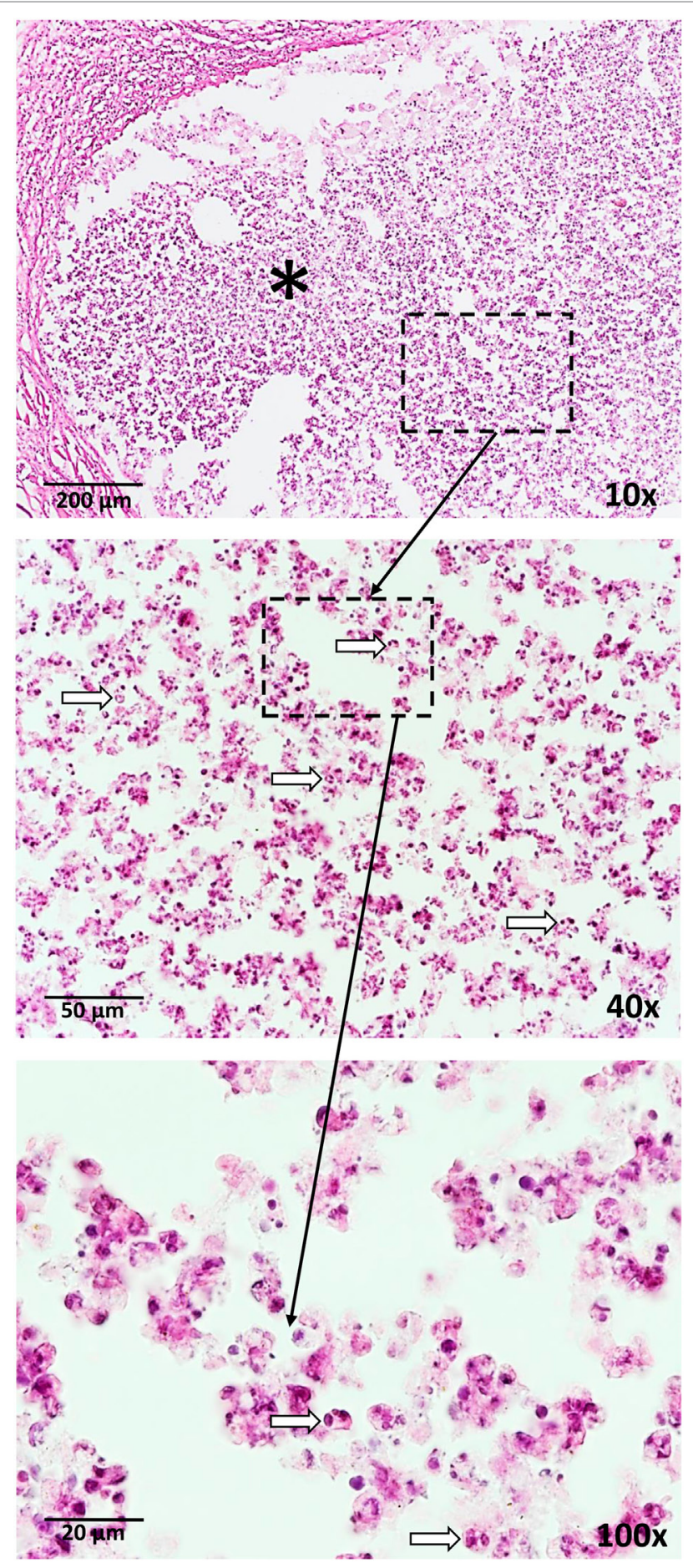

FIGURE 1 | Neutrophil influx (arrows) is a response to vaccination with BCG as well as a trehalose-6,6-dibehenate (TDB)-containing liposome-based adjuvant. The photographs are derived from skin tissue of mice, which were subcutaneously vaccinated with TDB liposomes containing ovalbumin at the tail base. Thirty-one days after vaccination, cryosections were stained with hematoxylin and eosin. * $=$ injection site.

awaits further analysis. After experimental administration of the recombinant $M$. smegmatis-based vaccine $\mathrm{mc}^{2}$-CMX, which expresses fragments of the M. tuberculosis antigens Ag85c,
MPT51, and HspX, and elicits specific Th1 and Th17 cells, neutrophil-rich lesions with a necrotic centers were observed (24). When neutrophils were depleted during vaccination, Th1- and Th17-specific responses, responsible for reduction of mycobacterial loads were nullified as were the protective efficacy of the $\mathrm{mc}^{2}$-CMX vaccine.

In contrast to immunity-promoting functions of neutrophils, effects detrimental for cellular and humoral immunity have also been described. Neutrophils can interfere with cell-mediated immunity upon adjuvant administration (25). Neutrophil depletion for the first $24 \mathrm{~h}$ after immunization restored $\mathrm{CD}^{+} \mathrm{T}$ and $B$ cell responses and improved clustering of antigen-specific $T$ cells with DCs, as shown by intravital microscopy. The strong suppressive effect of neutrophils on $\mathrm{T}$ and $\mathrm{B}$ cell activation depended on the small lipid mediators prostanoids since neutrophil influx into the lymph nodes was abrogated in cyclooxygenase (COX)-1 and -2 knock-out mice as well as when specific inhibitors for these two enzymes were applied (26). Inhibitors included COX1-selective SC-560, COX-2-selective NS-398, and Indomethacin. Specifically, the first wave of rapid neutrophil entry was dependent on prostaglandins, while the authors identified the neutrophilderived eicosanoid thromboxane $\mathrm{A}_{2}$ to control the extent of $\mathrm{T}$ cell responses. Indeed, thromboxane $\mathrm{A}_{2}$ has been shown to negatively regulate physical contact of DCs and T cells. Treatment by an exogenous thromboxane receptor agonist led to random, not chemokine gradient-guided $\mathrm{T}$ cell movement. Thromboxane receptor-deficient mice showed increased immune responses to a model antigen (27).

Taken together, these data demonstrate that neutrophil influxes and cross-talk between neutrophils and professional antigenpresenting cells can negatively influence $\mathrm{T}$ cell priming and proliferation upon vaccination. Importantly, neutrophil depletion or neutralization of neutrophil-derived immune mediators restored protective $\mathrm{T}$ cell responses upon adjuvants administration. Thus, targeting neutrophil-mediated regulation of the dendritic cell-T cell synapse may improve the establishment of adaptive immunity. Moreover, the neutrophils' short life span of only a few days suggests the type of cell death, e.g., immuno-silent apoptosis vs. immunogenic apoptosis vs. necrotic cell death, as an additional target during immune priming.

\section{IMPACT OF THE TYPE OF IMMUNE CELL DEATH ON VACCINE EFFICACY}

For a long time, apoptotic cell death has been thought to be immuno-silent or even anti-inflammatory. This paradigm shifted when it has been shown that the trigger of apoptosis shapes the immunological consequences thereof. For instance, Fas ligand-mediated apoptosis, e.g., of tumor cells, induces strong inflammatory responses through inflammasome activation, i.e., caspase-1 and its IL-1 $\beta$ - and IL-18-activating properties (28). Importantly, mycobacteria-infected macrophages succumbing to apoptosis deliver foreign antigens to dendritic cells and subsequently cross-prime antigen-specific T cells, thereby, establishing protection against experimental tuberculosis in mice (29, 30). Dendritic cells were activated by mycobacterial pathogenassociated molecular patterns carried along by apoptotic vesicles 
from infected cells. In contrast to virulent M. tuberculosis, BCG induces apoptosis in macrophages, especially upon IFN $\gamma$ activation (31). These findings are corroborated by us as well as others showing that attenuated M. tuberculosis strains as well as BCG primarily induce apoptosis in neutrophils, whereas virulent M. tuberculosis strains induce necrotic cell death in both, macrophages and neutrophils $(11,32-34)$. Moreover, apoptosis has been described as a defense mechanism against $M$. tuberculosis (35). In contrast, Aporta et al. report that BCG as well as the live attenuated vaccine candidate $M$. tuberculosis strain $\mathrm{SO}$, which lacks phoP, does not induce cell death (apoptosis or necrosis) in murine bone marrow-derived macrophages and the murine macrophage cell line J774, while the virulent parental clinical isolate MT103 induces apoptosis, but not necrosis (36). However, the contradicting findings regarding macrophage cell death induced by M. tuberculosis infection, i.e., necrosis vs. apoptosis, may be associated with the different mycobacterial strains (e.g., MT103, H37Rv, and Erdmann) or the macrophage types used (e.g., murine bone-marrow-derived, human monocyte-derived, murine, or human macrophage cell lines), respectively (37-39). Of note, the novel anti-tuberculosis vaccine candidate $M$. bovis BCG VPM that expresses listeriolysin but is deficient in urease, is a better inducer of macrophage apoptosis than the parental BCG strain (40).

The efficacy of whole cell anti-cancer vaccines has been shown to depend on the type of induced cell death prior to administration. In a prophylactic cancer vaccination study, apoptotic vs. necrotic tumor cells were studied for their efficacy to induce tumor antigen-specific T cells (41). Vaccination with $\gamma$-irradiated apoptotic tumor cells prevented tumor outgrowth in up to $100 \%$ of the mice. In contrast, mice that received necrotic tumor cells, generated by three freeze-thaw cycles, were protected in only $0-30 \%$ of the cases. The apoptotic tumor cell vaccine recruited predominantly dendritic cells as well as $\mathrm{CD} 4^{+}$and cytotoxic $\mathrm{CD}^{+} \mathrm{T}$ cells at the site of injection. Injection of necrotic tumor cells elicited strong macrophage influx. Apoptotic tumor cells increased the survival rates of mice. These data suggest that antigens delivered by apoptotic cells to antigen-presenting cells can result in a stronger $T$ cell response than those carried by necrotic cells (42). This notion is corroborated by a study, which combined dendritic cell-based immunotherapy with immunogenic cell death to successfully elicit Th1-mediated immunity to glioma (43). Application of necroptotic tumor cells also proved to be a successful vaccine strategy against cancer in mice. Induction of necroptosis in tumor cells by triggering RIPK3 resulted in the release of damage-associated molecular pattern molecules, subsequent dendritic cell activation, and priming of tumor antigen-specific IFN $\gamma$-producing T cell (44). Therefore, necroptotic tumor vaccines may also be employed, which comes in handy since many tumors are resistant to apoptosis induction.

These data indicate that the type of immune cell death upon whole cell anti-tumor vaccination shapes elicited immune responses. However, vaccination strategies, which determine the type of cell death of the antigen-bearing cells, may also improve anti-microbial vaccines. Application of an influenza vaccine with a microneedle following non-ablative fractional laser pretreatment triggered death of antigen-presenting cells and dsDNA release. This activated the cGAS/STING pathway and led to protective immunity (45). The use of this technique for BCG vaccination was effective without generating obvious inflammatory lesions (46). Analysis of the composition of infiltrating immune cells and their fate after tuberculosis vaccine application may improve vaccines by locally applying cell death inhibitors or inducers at the vaccination site. Upon immunization, programed cell death associated with the release of DAMPs promotes Th1-mediated immunity, whereas unregulated necrosis fails to induce $\mathrm{CD}^{+} \mathrm{T}$ cell responses. Certain self-lipid antigens have been shown to antagonize activation of T and natural killer (NK) T cells (47). One might envisage that oxidized lipid antigens, potentially generated during host phagocyte necrosis, interferes with induction of immunity by vaccination as discussed below.

\section{LIPID ANTIGEN ANTAGONISTS TO CONTROL VACCINATION EFFICACY?}

The ability of lipid antigens to prime-specific $\mathrm{T}$ cells upon presentation by myeloid antigen-presenting cells via highly conserved CD1 molecules indicates the possibility of mycobacterial lipid-based vaccinations in an $\mathrm{MHC}$-independent manner. Human antigen-presenting cells can express four CD1 isoforms $(\mathrm{CD} 1 \mathrm{a}-\mathrm{d})$ that bind a variety of exogenous and endogenous lipid compounds (48-50). The relevance of CD1-restricted lipid antigens for $\mathrm{T}$ cell immunity has been well characterized for autoimmune diseases (51), cancer (52), and infections (53).

Human CD1b can bind and present mycobacterial antigens including mycolic acids and glucose monomycolate to $\mathrm{T}$ cells in vitro (54). Other CD1b ligands include mycobacterial diacylated sulfoglycolipids ( $\mathrm{Ac}_{2} \mathrm{SGL}$ ) and phosphatidyl-myo-inositol dimannosides $\left(\mathrm{PIM}_{2}\right)$ (55). Furthermore, $\mathrm{CD} 1^{+}$dendritic cells have been isolated in great numbers from leprosy skin lesions upon $M$. leprae infection, which was associated with active cellular immune response (56). Importantly, mycobacterial lipid antigen-reactive $\mathrm{T}$ cells were identified in blood of patients with latent and active, antibiotic-treated tuberculosis (57).

Emphasizing lipid antigen involvement in mycobacterial immune responses, direct immunization of guinea pigs with a mixture of mycobacterial lipid antigens induced CD4-negative cytotoxic $\mathrm{T}$ cells reacting to $\mathrm{CD} 1$-expressing, mycobacterial antigen-presenting dendritic cells (58). Another study found that vaccination of guinea pigs with $M$. tuberculosis lipids-containing liposomes in combination with a non-lipid adjuvant, prior to $M$. tuberculosis infection, reduced pathology and mycobacterial loads, presumably due to CD1-restricted $\mathrm{T}$ cell responses (59). Similar protection was observed in guinea pigs by a vaccine combining $\mathrm{Ac}_{2} \mathrm{SGL}$ and $\mathrm{PIM}_{2}$ (60). Especially, $\mathrm{Ac}_{2} \mathrm{SGL}$ showed promising results, activating human $\mathrm{CD} 1$-restricted $\mathrm{CD} 8^{+} \mathrm{T}$ cells in vitro isolated from skin test-positive donors (55). However, long-term memory protection was not detected even though glycolipid-specific immunoglobulin responses can occur after lipid antigen presentation $(61,62)$. To induce memory B cell responses against lipids, well-established anti-protein vaccine formulations were combined with glycolipids by conjugating 
glucose monomycolate to a carrier protein (63). Disappointingly, anti-glucose monomycolate antibody responses were not induced.

Even though indications for protective effects upon immunization with mycobacterial lipid antigens were observed, detailed knowledge of the mechanisms, interaction characteristics, and downstream effects remain largely unknown. Most studies based on mycobacterial lipid vaccination, lack data on long-term memory responses, and prolonged immunity to tuberculosis.

Besides exogenous lipids, all CD1 molecules can bind and present a broad variety of endogenous, self-derived phospholipids, and glycosphingolipids with differential effects on subsequent $\mathrm{T}$ cell activation. Endogenous skin lipids presented by antigen-presenting cells via human CD1a molecules have been shown to either inhibit or stimulate $\mathrm{T}$ cell responses dependent on the structural properties and charges of the lipid antigen. In contrast to lipids with hydrophilic head groups that protrude into the binding groove of CD1 and, thus, prevent T cell receptor binding and subsequent $\mathrm{T}$ cell activation, highly apolar lipids placed deep in the binding groove, facilitated strong $\mathrm{T}$ cell receptor binding, and induced an autoreactive phenotype of CD1a-restricted T cells (48). Therefore, autoreactive T cells can become activated upon a shift toward a hydrophobic head group lipid composition, which may occur during certain autoimmune skin diseases $(64,65)$. Self-derived lipid antigens also indirectly influence the presentation of mycobacterial lipids and downstream signaling. Structural crystallography analysis revealed that $\mathrm{CD} 1 \mathrm{~b}$ adapts to different sizes and numbers of mycobacterial lipid alkyl chains by capturing small endogenous gangliosides, thus, stabilizing the CD1-lipid complex (66). Huang et al. identified deoxyceramides and diacylglycerols species as scaffolding lipids (47). They were found to nest deeply into the binding groove of CD1 molecules and, thereby, affect binding of exogenous mycobacterial lipid antigens. The efficacy of interference depended on the length of the hydrophobic side domains. Hydrophobic long alkyl side chains, protruding into the binding groove, inhibited $\mathrm{T}$ cell activation, whereas those with short hydrophobic domains stabilized the lipid-CD1 complex and facilitated T cell activation (47). These studies strongly suggest that the immune system is able to sense inflammationinduced changes of the lipidome within affected tissues, which in turn modulates immune responses. Inhibition of CD1-T cell receptor interaction by protruding lipids interrupts $\mathrm{T}$ cell activation. Therefore, self-derived lipids, serving either as scaffolding molecules or as auto-antigens, may function as agonists or antagonists for downstream $\mathrm{T}$ cells activation depending on their molecular structure. Recent studies tried to utilize these findings for development of new therapeutics. CD1d-restricted invariant NK T cells were strongly activated to produce Th1 and Th2 cytokines by recognition of a CD1d- $\alpha$-galactosylceramide complex (67) indicating $\alpha$-galactosylceramide as a putative adjuvant for vaccination. Addition of a phenyl group or a shorter phytosphingosine chain, as in the analog $\mathrm{OCH}$, changes CD1d-antigen complexes on antigen-presenting cells and shifts downstream NKT cell responses to either IFN $\gamma$ or IL-4 production, respectively (67). These modifications can shape immune responses including prevention of autoimmunity, such as experimental autoimmune encephalomyelitis in mice (68) and improved cancer therapy by induction of NKT cell-driven Th1 responses $(69,70)$ suggesting that $\mathrm{CD} 1$-lipid-T cell receptor interactions can be targeted to improve vaccine efficacy.

Upon release of reactive oxygen species, human neutrophils oxidized self-lipids by their own myeloperoxidase $(71,72)$. Initial oxidation by a single free radical could trigger an oxidization cascade, which proceeds within biological membranes, resulting in accumulation of oxidized lipid species by just one hit (73). Importantly, we have shown that human neutrophils underwent necrotic cell death upon infection with $M$. tuberculosis that was dependent on myeloperoxidase-generated reactive oxygen species (32). Therefore, infected necrotic neutrophils, which are removed by myeloid cells capable to present antigens via CD1 molecules, represent a source of oxidized self-lipids that potentially interfere with $\mathrm{T}$ cell responses to mycobacteria. Exogenous and endogenous lipid antigens are interesting compounds to control CD1 antigen presentation and, thereby, silencing or activating CD1-restricted $\mathrm{T}$ cell responses in order to modulate immunity against mycobacteria during infection or vaccination with whole attenuated mycobacteria. Interestingly, CD1-restricted M. tuberculosis-as well as pollen lipid-specific $\mathrm{T}$ cells have been shown to produce the anti-inflammatory cytokine IL-10 $(74,75)$, which is able to interfere with BCG vaccination efficacy $(76,77)$.

\section{NEUTRALIZING ANTI-INFLAMMATORY IL-10}

Immune responses during infection have to be tightly controlled in order to avoid excessive inflammation and subsequent tissue damages. Anti-inflammatory cytokines such as IL-10 prevent immunopathology by restraining both, Th1 and Th17 cell activities (78). Due to its negative effect on protective adaptive immune responses, IL-10 signaling has been associated with detrimental course of infection in experimental tuberculosis in mice $(77,79)$. Importantly, increased IL-10 production upon vaccination against various pathogens was shown to limit their protective efficacy $(80,81)$. Several studies reported induction of IL-10 upon BCG challenge in both, humans and mice (82-85). IL-10-deficient mice vaccinated with BCG revealed higher splenocyte numbers generating IFN- $\gamma$, IL-17A, and TNF- $\alpha$ when compared with wild-type ones $(76,77)$. Accordingly, BCGvaccinated mice were better protected against $M$. tuberculosis infection after treatment with an IL-10-neutralizing antibody $(76,77)$. Thus, controlled short-term regulation of IL-10 levels during BCG vaccination represents a promising host-directed immune modulation to expedite mycobacterial clearance, establish better $\mathrm{T}$ cell-mediated immunity and thereby improve vaccination efficacy.

Agonists for C-type lectin receptors, particularly trehalose dibehenate (TDB), have been highlighted as promising adjuvant candidates for anti-tuberculosis vaccination (86). TDB is the synthetic analog of the mycobacterial cell wall glycolipid trehalose-6,6'-dimycolate (TDM), which binds to the macrophage-inducible C-type lectin, also known as Mincle, 
and subsequently induce pro-inflammatory cytokine secretion $(16,87,88)$. Interestingly, Lindenstrom et al. demonstrated that CAF01, a liposome preparation containing TDB, could trigger potent and sustained Th1 and Th17 responses (86). Mincle was identified as target for vaccine adjuvants with strong immunogenic properties against $M$. tuberculosis infection in mice (89). We recently showed that Mincle signaling was also critical for IL-10 secretion in response to TDM or BCG challenge in vitro (90). Our studies demonstrated that IL-10 secretion down-regulated IL-12 production, a pivotal cytokine for proper induction of Th1 responses (91). Thus, it would be interesting to investigate whether anti-tuberculosis vaccines including those formulated with TDB or other Mincle ligands can be combined with antiIL-10 antibodies to improve both, efficacy and duration of protection against $M$. tuberculosis. It remains to be elucidated whether this approach can be extended to other anti-inflammatory cytokines such as TGF- $\beta$ and IL-27. In conclusion, controlled short-term down-regulation of IL-10 levels after vaccination may be a promising host-directed modulation to drive a Th1-/Th17mediated memory response and promote long-term immunity. In this context, regulation of immune cell populations that interfere with developing Th1-derived protection upon vaccination, e.g., myeloid-derived suppressor cells (MDSC) and regulatory $\mathrm{T}$ cells $\left(\mathrm{T}_{\mathrm{regs}}\right)$, have the potential as pharmaceutically controllable switch points to improve long-term vaccine efficacy.

\section{CONTROLLING Th1-SUPRESSING IMMUNE CELL SUBPOPULATIONS}

Depletion of immune cell subsets, such as MDSC and $\mathrm{T}_{\text {regs }}$ by monoclonal antibodies have been shown to improve clinical outcome and vaccination efficacy (92). Increased frequencies of MDSC have been shown in blood samples and at the site of M. tuberculosis infection in chronic as well as recently infected patients (93-95). MDSC suppressed $\mathrm{CD}^{+}$and $\mathrm{CD}^{+} \mathrm{T}$ cell proliferation and cytokine secretion ex vivo. After successful anti-tuberculosis treatment, MDSC frequencies became normalized accompanied by MDSC maturation as indicated by expression of co-stimulatory surface molecule CD80. Importantly, when MDSC were depleted in M. tuberculosis-infected mice by administration of all-trans retinoic acid, mycobacterial burden, and pathology in lungs were reduced (96). In tumorbearing mice, researchers found that MDSC migrate along a gradient of the pro-inflammatory alarmin S100A8/9 leading to MDSC accumulation (97). Blockade of S100A8/9 binding to MSDC resulted in decreased frequencies of MDSC. Moreover, mice deficient for S100A9 generated potent tumor rejection responses, while S100A9 overexpression led to accumulation of MDSC and reduced numbers of differentiated dendritic cells and macrophages. Of note, S100A8/9 comprise $45 \%$ of all cytosolic proteins in neutrophils, while its amount is $40 \times$ lower in monocytes (98). As mentioned above, massive infiltration of neutrophils at the site of BCG vaccination as well as M. tuberculosis infection may be the reason for the reported upregulated levels of S100A8/9 during tuberculosis $(99,100)$, which may result in accumulation of MDSC and, ultimately, suppression of proper
Th1 immune responses. Indeed, S100A8/9, specifically derived from neutrophils, was responsible for diabetes-induced thrombocytosis (101). Blockade of S100A8/9 binding to its receptor by administration of Paquinimod was beneficial. Specific inhibition of S100A8/9 by Paquinimod reduced inflammation and pathology under various disease conditions, including leukocyte recruitment during sterile inflammation, experimental systemic sclerosis, and experimental osteoarthritis (102-105). Therefore, MDSC may represent the S100A8/9-driven connection that links massive neutrophil influx to impaired Th1 immune responses and memory phenotypes thereof. Vaccination efficacy may benefit from treatments regulating MDSC influx or their maturation during vaccination-induced immune priming.

Another immune cell subpopulation playing a detrimental role in the successful establishment of Th1-mediated control of $M$. tuberculosis infection are $\mathrm{T}_{\text {regs. }}$. Increased frequencies of FoxP3 ${ }^{+}$, IL-10-, and TGF $\beta$-releasing $\mathrm{T}_{\text {regs }}$ have been found in peripheral blood and at the site of infection in tuberculosis patients (106-108). After successful treatment, those frequencies decreased to similar levels as in healthy controls (108). For mice, it has been shown that $\mathrm{T}_{\text {regs }}$ are responsible for impaired generation of protective immunity against tuberculosis. After aerosol infection of mice, preexisting $M$. tuberculosis-specific $\mathrm{T}_{\text {regs }}$ expanded in the draining lymph nodes (109). Accumulation of those $\mathrm{T}_{\text {regs }}$ in the lungs resulted in delayed arrival of pathogenspecific IFN $\gamma$-producing $\mathrm{CD}^{+}$and $\mathrm{CD}^{+}$effector $\mathrm{T}$ cells and suppression of protective immunity. Induced expansion of both, $\mathrm{T}_{\text {regs }}$ and IFN $\gamma$-, perforin-producing $\mathrm{T}$ effector cells by s.c. administration of rIL-2 led to accumulation of those subsets in the lungs of M. tuberculosis-infected macaques (110). Interestingly, infiltrating Th1 effector cells and $\mathrm{T}_{\text {regs }}$ orchestrated both, control of M. tuberculosis burdens as well as resistance to severe inflammation and tissue damage. Targeted inhibition of Th2 and $\mathrm{T}_{\text {regs }}$ generation by administration of the small compounds suplatast tosylate and D4476 reduced M. tuberculosis burden and established a protective Th1 immune response (111). The same research group shows in a follow-up study that the same treatment enhanced BCG efficacy upon vaccination so that $M$. tuberculosis burdens were reduced in lungs and spleens of mice after infection (112). Mycobacteria-specific $\mathrm{T}_{\text {regs }}$ already occur after administration of commonly used BCG formulations as well as during clinical trials with novel candidate vaccines (113). To enhance vaccine efficacy and Th1-mediated immunity upon BCG vaccination against $M$. tuberculosis infection, $\mathrm{T}_{\text {regs }}$ have been successfully targeted. Dhiman et al. showed that human $\mathrm{NK}_{1.1^{+}} \mathrm{NK}$ cells promoted $\mathrm{CD} 8^{+} \mathrm{T}$ cell responses and concomitantly reduced frequencies of $M$. tuberculosisspecific $\mathrm{T}_{\text {regs }}$ in an IL-22-dependent manner (114). BCG vaccination of mice generated those IL-22- and IFN $\gamma$ - secreting NK cells and their specific depletion upon vaccination led to higher numbers of $\mathrm{T}_{\text {regs }}$, increased mycobacterial burden, and reduced $\mathrm{T}$ cell responses after $M$. tuberculosis infection. More importantly, concomitant administration of rIL-22 and BCG in $\mathrm{NK} 1.1^{+}$cell-depleted animals restored $\mathrm{CD}^{+} \mathrm{T}$ cell responses and BCG vaccination efficacy, indicating that IL-22 treatment can improve vaccination efficacy. Another study shows that a novel subunit vaccine booster candidate induced strong and 
specific Th1-mediated IFN $\gamma$ and IL-2 production, while $\mathrm{T}_{\text {regs }}$ were down-regulated (115). This formulation included a fusion protein of Ag85B, Mpt64, and Mtb8.4 formulated in an adjuvant containing dimo-thylidioctyl ammonium bromide and BCGpolysaccharide-nucleic acid, consisting of polysaccharides and nucleic acids extracted from BCG. Finally, subsequent administration of a $\mathrm{T}_{\text {regs }}$-depleting anti-CD25 antibody upon BCG vaccination, resulted in an increased IFN $\gamma$ response, and reduced mycobacterial load upon M. tuberculosis infection (116).

Thus, temporal regulation of highly relevant immune subpopulations, such as MDSC and $\mathrm{T}_{\text {regs }}$ that otherwise modulate immune responses and protect from exacerbated inflammatory tissue destruction, may display a crucial step in shifting the immune memory toward a protective Th1 response upon vaccination with BCG-based vaccines. Besides other T cell populations, which also modulate immune responses upon vaccination, but have been comprehensively reviewed before (117-119), an innate lymphoid cell population, namely NK cells, has recently found its way into the spotlight of tuberculosis research.

\section{NATURAL BORN KILLERS}

Because of their ability to rapidly induce cell death without the need of further activation, for instance in response to virus infected cells and tumor cells, NK cells were classified as innate lymphoid cell population (120). However, upon infection, NK cells were found to display a memory-like phenotype providing so-called innate memory (121-123). This phenomenon has also been described upon M. tuberculosis infection (124). For instance, NK cells recovered from pleural fluid from tuberculosis patients were a major source of IFN- $\gamma$ as well as IL-22 production when restimulated with $M$. tuberculosis ex vivo $(125,126)$. In murine tuberculosis models but also in patients latently infected with $M$. tuberculosis, NK cells expand, mature, and produce IFN- $\gamma$ upon both, $M$. tuberculosis infection and BCG vaccination $(127,128)$. Venkatasubramanian et al. found reduced mycobacterial burden in the lungs of $M$. tuberculosisinfected C57 BL/6 mice after adoptive transfer of NK cells that matured and expanded in response to BCG vaccination. This observation is in contrast to findings by Junqueira-Kipnis et al. reporting similar lung CFUs of $M$. tuberculosis-infected C57 BL/6 mice after antibody-mediated depletion of NK cells, suggesting a priming effect of BCG, which induces a memory-like NK cell popuation. Thus, a potential protective role for NK cells during $M$. tuberculosis infection, especially in human individuals, requires further investigations (129). Indeed, a recent phase 1 clinical trial with 72 tuberculin skin test-positive participants from South Africa revealed that re-vaccination with BCG boosted frequencies of IFN $\gamma$-secreting NK cells in response to BCG (130). Notably, this was in contrast to BCG-specific CD4, CD8 as well as $\gamma \delta$ T cells, which numbers were only transiently enhanced after re-vaccination. Sustained elevated frequencies of NK cells were still observed after 1 year.

The memory-like phenotype of NK cells in response to BCG is based on epigenetic reprogramming, a phenomenon also termed "trained immunity" (131) that has been observed also for myeloid-derived innate immune cells.

\section{TRAINING INNATE IMMUNITY TO BOOST VACCINE EFFICACY}

The ability to develop an immunological memory has been attributed exclusively to lymphoid cells of the adaptive immune system, i.e., $\mathrm{T}$ and $\mathrm{B}$ cells. Recently, memory properties have also been described for prototypical cells of the innate immune system, namely macrophages and monocytes among others (132). Beneficial effects of BCG vaccination on several unrelated diseases, including non-mycobacterial infections, allergies, and cancer, in an antigen-independent manner have been comprehensively reviewed elsewhere with regard to innate memory characteristics (133-135). For instance, monocytes of BCG-vaccinated healthy individuals produced more IFN- $\gamma$, $\mathrm{TNF} \alpha$, and IL- $1 \beta$ in response to otherwise unrelated bacterial or fungal pathogens compared with the unvaccinated control group (136). The same study showed that $100 \%$ of severe combined immunodeficiency mice were protected from disseminated candidiasis after vaccination with BCG compared with only $30 \%$ of non-vaccinated mice. The authors conclude that BCG vaccination can instruct innate immune cells through epigenetic reprogramming based on histone methylation to provide antigen-independent protection in an NOD1 signaling pathway-dependent manner.

It remains to be elucidated whether targeting innate memory can be employed to improve anti-M. tuberculosis vaccination. As reviewed by Netea and van Crevel, several studies revealed that BCG-vaccinated household contacts, either juvenile or adults, of active tuberculosis patients were significantly less often interferon-gamma release assay (IGRA)-positive than non-vaccinated individuals, which was even more striking after a second BCG boost (133). The authors suggest that innate immune cells trained by BCG vaccination are able to eliminate $M$. tuberculosis before adaptive immunity kicks in leaving these individuals IGRA-negative, whereas those failing to clear the initial infection turn IGRA-positive. Corroborating these observations, Kagina et al. showed that house hold contacts of tuberculosis patients, which did not develop active tuberculosis, did not have increased mycobacteria-specific $\mathrm{T}$ cell responses (137). Thus, the capability of humans to control $M$. tuberculosis is not necessarily correlated with enhanced immune protection by antigen-specific $\mathrm{T}$ cells and, therefore, indicates the relevance of vaccination-triggered innate immune activation for clearance of an initial infection or, at least, reduction of the infection dose. Subsequent boost of acquired immune control may lead to latent tuberculosis without pathogen elimination. Identification of the vaccine associated triggers for innate immune cell training may thereby help to design better vaccine formulations to protect against active tuberculosis.

\section{HOST-DIRECTED IMMUNE MODULATION TO IMPROVE VACCINATION SUCCESS}

Concomitant administration of immune-modulating factors together with a vaccine has been studied mainly in other 
fields than tuberculosis. Especially in experimental cancer therapy, blockade of anti-inflammatory cytokines and $\mathrm{T}$ cell inhibitory receptors, such as TGF- $\beta$, programmed death-1, and CTLA4, respectively, resulted in increased T cell-mediated tumor regression $(138,139)$. Interestingly, administration of drugs that systemically suppress certain immune responses, namely the COX-2 inhibitors celecoxib and NS-398, enhanced tumor vaccine efficacies against breast cancer and pancreatic adenocarcinoma (140-142). Treatment of HIV patients with a COX inhibitor rescued $\mathrm{T}$ cell functions and humoral memory

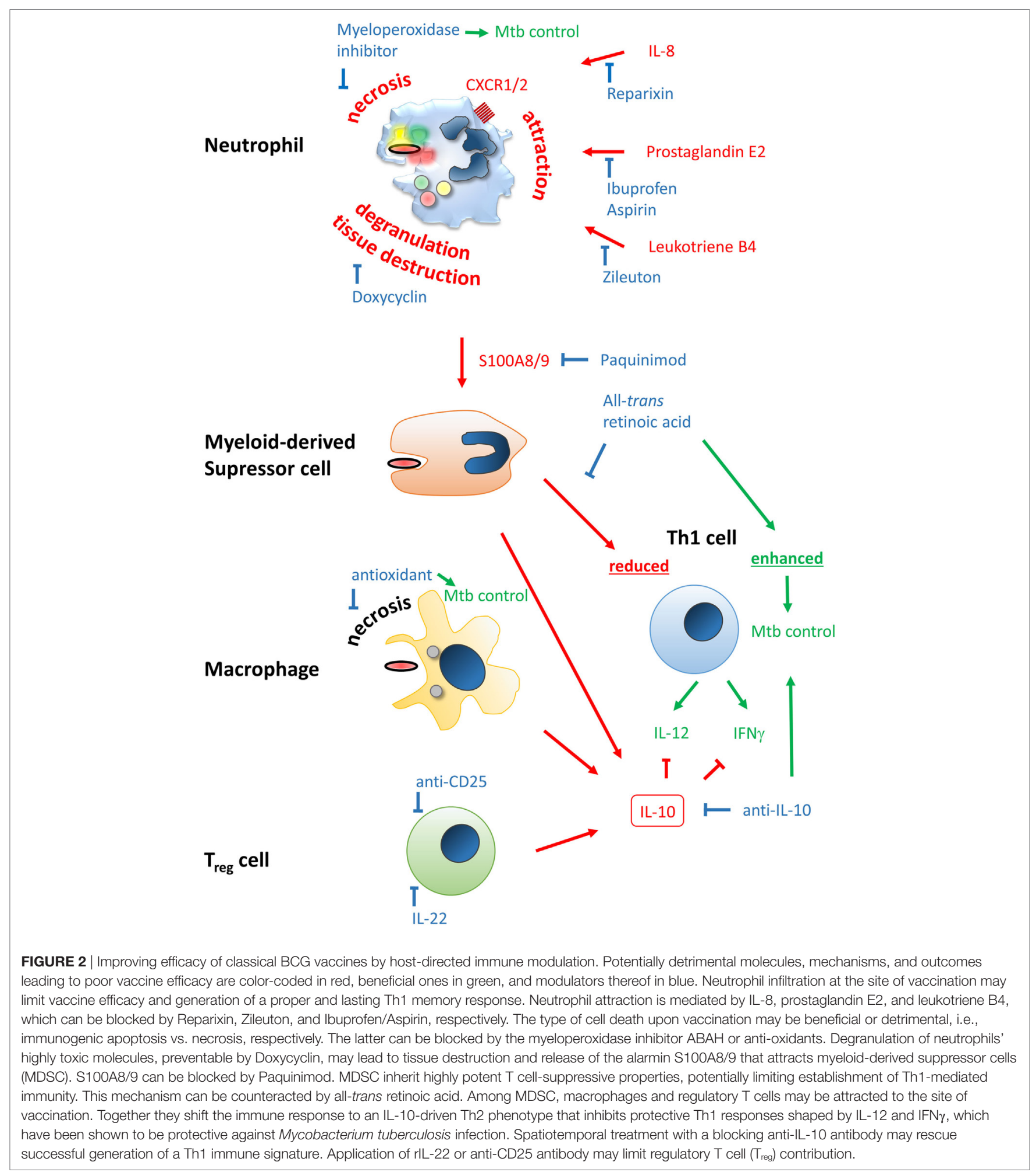


responses to tetanus toxoid, a T cell targeting vaccine (143). Of note, small lipid mediators produced by the cyclooxygenease pathway have been shown to attract neutrophils to the site of M. tuberculosis infection (13). Inhibition of neutrophil infiltration by Ibuprofen ameliorated tuberculosis pathogenesis and mycobacterial loads in susceptible $\mathrm{C} 3 \mathrm{HeB} / \mathrm{FeB}$ mice and, therefore, may be exploitable to improve anti-tuberculosis vaccines including BCG.

Macrophage responses may also serve as targets for hostdirected therapies accompanying anti-tuberculosis vaccination. Taus et al. found that pretreatment of THP-1 cells with monosodium urate (MSU) crystals resulted in enhanced ROS production, promotion of phagosome-lysosome fusion, and increased killing of BCG by those cells, likely in an NODlike receptor-mediated inflammasome-triggering process (144). MSU alone had no effect on BCG viability, indicating its pro-inflammatory properties, and capability to enhance anti-microbial responses. Moreover, BCG vaccination in the presence of MSU resulted in reduced colony-forming units in draining lymph nodes, showing increased killing of BCG in vivo. Again, BCG viability within the vaccine formulation was not affected by MSU. Interestingly, when mice were infected with M. tuberculosis Erdmann 10 weeks after vaccination, $M$. tuberculosis burden was reduced in the lungs and spleens, when the BCG vaccine was complemented with MSU in comparison with BCG alone. These findings raise the question, if enhanced killing of BCG upon vaccination, which is considered to counteract the maintenance of long-term immunity, may improve vaccine efficacy.

In another approach, the autophagy-inducing drug Rapamycin was used to successfully enhance processing and presentation of Ag85B by murine antigen-presenting cells (145). Immunization with Rapamycin treated dendritic cells led to increased Th1mediated protection from M. tuberculosis infection. Thus, BCG vaccine efficacy may be enhanced by concomitant augmentation of autophagy.

Only a few studies assessed immune-modulatory approaches upon vaccination against tuberculosis. Surprisingly, repeated vaccine injections of BCG in already $M$. tuberculosis-infected $\mathrm{BALB} / \mathrm{c}$ mice resulted in increased levels of IL-17, neutrophil influx into the lung, and tissue damage (146). This detrimental outcome of vaccination had been prevented by concomitant administration of a blocking anti-IL-17 antibody. Host-directed modulation of IL-17 upon vaccine treatment may have important implications for vaccinations in individuals that are already infected with $M$. tuberculosis.

Although there is only a small amount of data available, few publications show promising first results for increasing BCG vaccine efficacy by adjunct modulation of the host immune system. However, we can probably learn from data derived from tumor vaccination and other non-infectious disease vaccines boosted by concomitant immunotherapy. These results will be instrumental to develop novel strategies by temporarily adjusting the immune network to favor a long-term protective memory immune response against tuberculosis (Figure 2). Re-purposing already known host-directed therapeutics for anti-tuberculosis vaccination strategies may improve the protective efficacy, even of the "old" BCG.

\section{CONCLUSION}

So far, novel strategies to boost vaccine efficacy against tuberculosis are based on enhancement of the BCG vaccine by addition of antigens that are expressed by $M$. tuberculosis, but not $M$. bovis BCG, e.g., ESX-1 secretion-mediating ESAT-6, TDM-synthesizing Ag85, and ESX-5-associated PE/PPE, or by genetically modifying BCG to express immunity-promoting mediators such as GM-CSF or IL-2 $(147,148)$. To improve vaccination efficacy against $M$. tuberculosis infection, focusing on more $M$. tuberculosis antigens may enhance the frequency of specific T cells, but may not solve the problem that BCG and next generation anti-TB vaccine types also elicit immunomodulatory functions that hamper immune-priming efficacy. Short-term shapeshift of the local immune responses upon vaccination may result in far-reaching long-term consequences for establishment of protective memory immunity against M. tuberculosis infection. These immune modulations may include regulation of neutrophil and MDSC influx to the site of vaccine application, prevention of detrimental kinds of cell death that interfere with generation of a protective memory immune response, and facilitation of other beneficial types of cell death, interference with $\mathrm{T}$ cell-inhibiting presentation of (self-)lipids after vaccination-mediated inflammation, temporal regulation of adverse, anti-inflammatory cytokine profiles, e.g., IL-10, and spatiotemporal modulation of immune cell subpopulations that suppress $\mathrm{T}$ effector cells, like $\mathrm{T}_{\text {regs }}$ and MDSC. Promising results of immune modulation during vaccination in other application areas, namely cancer vaccine research, highlight the potential of such host-directed improvements.

\section{AUTHOR CONTRIBUTIONS}

LL wrote the chapter "Lipid antigen antagonists to control vaccination efficacy?" EP wrote the chapter "Neutralizing antiinflammatory IL-10 to improve vaccination success." US and TD wrote all other parts of the manuscript and supervised the process. NR contributed Figure $\mathbf{1}$ and its legend. Additionally, TD contributed Figure 2 and its legend.

\section{FUNDING}

For financial support, we thank foremost the Priority Program 1580 "Intracellular compartments as places for pathogenhost interactions" and additionally the Excellence Cluster "Inflammation at Interfaces" and the IRTG 1911, all funded by the Deutsche Forschungsgemeinschaft, as well as the Deutsche Bundesministerium für Bildung und Forschung (BMBF)-funded "Deutsches Zentrum für Infektionsforschung" (TTU-TB) and “TBSequel," a project within the BMBF Africa program. 


\section{REFERENCES}

1. WHO. World Health Organization: Global Tuberculosis Report. 20th ed. Geneva: WHO Press (2016).

2. Mangtani P, Abubakar I, Ariti C, Beynon R, Pimpin L, Fine PE, et al. Protection by BCG vaccine against tuberculosis: a systematic review of randomized controlled trials. Clin Infect Dis (2014) 58:470-80. doi:10.1093/ $\mathrm{cid} / \mathrm{cit} 790$

3. Tameris MD, Hatherill M, Landry BS, Scriba TJ, Snowden MA, Lockhart S, et al. Safety and efficacy of MVA85A, a new tuberculosis vaccine, in infants previously vaccinated with BCG: a randomised, placebo-controlled phase $2 \mathrm{~b}$ trial. Lancet (2013) 381:1021-8. doi:10.1016/S0140-6736(13)60177-4

4. Belisle JT, Vissa VD, Sievert T, Takayama K, Brennan PJ, Besra GS. Role of the major antigen of Mycobacterium tuberculosis in cell wall biogenesis. Science (1997) 276:1420-2. doi:10.1126/science.276.5317.1420

5. McShane H, Pathan AA, Sander CR, Keating SM, Gilbert SC, Huygen K, et al. Recombinant modified vaccinia virus Ankara expressing antigen 85A boosts BCG-primed and naturally acquired antimycobacterial immunity in humans. Nat Med (2004) 10:1240-4. doi:10.1038/nm1128

6. Upadhyay P. Tuberculosis vaccine trials. Lancet (2013) 381:2253-4. doi:10.1016/ S0140-6736(13)61482-8

7. Andersen P, Doherty TM. The success and failure of BCG-implications for a novel tuberculosis vaccine. Nat Rev Microbiol (2005) 3:656-62. doi:10.1038/ nrmicro1211

8. Eum SY, Kong JH, Hong MS, Lee YJ, Kim JH, Hwang SH, et al. Neutrophils are the predominant infected phagocytic cells in the airways of patients with active pulmonary TB. Chest (2010) 137:122-8. doi:10.1378/ chest.09-0903

9. Berry MP, Graham CM, Mcnab FW, Xu Z, Bloch SA, Oni T, et al. An interferon-inducible neutrophil-driven blood transcriptional signature in human tuberculosis. Nature (2010) 466:973-7. doi:10.1038/nature09247

10. Gopal R, Monin L, Torres D, Slight S, Mehra S, McKenna KC, et al. S100A8/A9 proteins mediate neutrophilic inflammation and lung pathology during tuberculosis. Am J Respir Crit Care Med (2013) 188:1137-46. doi:10.1164/rccm.201304-0803OC

11. Dallenga T, Schaible UE. Neutrophils in tuberculosis-first line of defence or booster of disease and targets for host-directed therapy? Pathog Dis (2016) 74:ftw012. doi:10.1093/femspd/ftw012

12. Irwin SM, Gruppo V, Brooks E, Gilliland J, Scherman M, Reichlen MJ, et al. Limited activity of clofazimine as a single drug in a mouse model of tuberculosis exhibiting caseous necrotic granulomas. Antimicrob Agents Chemother (2014) 58:4026-34. doi:10.1128/AAC.02565-14

13. Vilaplana C, Marzo E, Tapia G, Diaz J, Garcia V, Cardona PJ. Ibuprofen therapy resulted in significantly decreased tissue bacillary loads and increased survival in a new murine experimental model of active tuberculosis. J Infect Dis (2013) 208:199-202. doi:10.1093/infdis/jit152

14. Yeremeev V, Linge I, Kondratieva T, Apt A. Neutrophils exacerbate tuberculosis infection in genetically susceptible mice. Tuberculosis (Edinb) (2015) 95:447-51. doi:10.1016/j.tube.2015.03.007

15. Abadie V, Badell E, Douillard P, Ensergueix D, Leenen PJ, Tanguy M, et al. Neutrophils rapidly migrate via lymphatics after Mycobacterium bovis BCG intradermal vaccination and shuttle live bacilli to the draining lymph nodes. Blood (2005) 106:1843-50. doi:10.1182/blood-2005-03-1281

16. Schoenen H, Bodendorfer B, Hitchens K, Manzanero S, Werninghaus K, Nimmerjahn F, et al. Cutting edge: Mincle is essential for recognition and adjuvanticity of the mycobacterial cord factor and its synthetic analog trehalose-dibehenate. J Immunol (2010) 184:2756-60. doi:10.4049/jimmunol. 0904013

17. MalettoBA, RopoloAS, AlignaniDO,LiscovskyMV, RanocchiaRP,MoronVG, et al. Presence of neutrophil-bearing antigen in lymphoid organs of immune mice. Blood (2006) 108:3094-102. doi:10.1182/blood-2006-04-016659

18. Puga I, Cols M, Barra CM, He B, Cassis L, Gentile M, et al. B cell-helper neutrophils stimulate the diversification and production of immunoglobulin in the marginal zone of the spleen. Nat Immunol (2011) 13:170-80. doi:10.1038/ ni.2194

19. Nagelkerke SQ, Aan De Kerk DJ, Jansen MH, Van Den Berg TK, Kuijpers TW. Failure to detect functional neutrophil B helper cells in the human spleen. PLoS One (2014) 9:e88377. doi:10.1371/journal.pone.0088377
20. Achkar JM, Chan J, Casadevall A. B cells and antibodies in the defense against Mycobacterium tuberculosis infection. Immunol Rev (2015) 264:167-81. doi:10.1111/imr.12276

21. Jacobs AJ, Mongkolsapaya J, Screaton GR, McShane H, Wilkinson RJ. Antibodies and tuberculosis. Tuberculosis (Edinb) (2016) 101:102-13. doi:10.1016/j.tube.2016.08.001

22. Matsushima H, Geng S, Lu R, Okamoto T, Yao Y, Mayuzumi N, et al. Neutrophil differentiation into a unique hybrid population exhibiting dual phenotype and functionality of neutrophils and dendritic cells. Blood (2013) 121:1677-89. doi:10.1182/blood-2012-07-445189

23. Di Pilato M, Mejias-Perez E, Zonca M, Perdiguero B, Gomez CE, Trakala M, et al. NFkappaB activation by modified vaccinia virus as a novel strategy to enhance neutrophil migration and HIV-specific T-cell responses. Proc Natl Acad Sci U S A (2015) 112:E1333-42. doi:10.1073/pnas.1424341112

24. Trentini MM, De Oliveira FM, Kipnis A, Junqueira-Kipnis AP. The role of neutrophils in the induction of specific Th1 and Th17 during vaccination against tuberculosis. Front Microbiol (2016) 7:898. doi:10.3389/fmicb 2016.00898

25. Yang CW, Strong BS, Miller MJ, Unanue ER. Neutrophils influence the level of antigen presentation during the immune response to protein antigens in adjuvants. J Immunol (2010) 185:2927-34. doi:10.4049/jimmunol.1001289

26. Yang CW, Unanue ER. Neutrophils control the magnitude and spread of the immune response in a thromboxane A2-mediated process. J Exp Med (2013) 210:375-87. doi:10.1084/jem.20122183

27. Kabashima K, Murata T, Tanaka H, Matsuoka T, Sakata D, Yoshida N, et al. Thromboxane A2 modulates interaction of dendritic cells and $\mathrm{T}$ cells and regulates acquired immunity. Nat Immunol (2003) 4:694-701. doi:10.1038/ ni943

28. Restifo NP. Building better vaccines: how apoptotic cell death can induce inflammation and activate innate and adaptive immunity. Curr Opin Immunol (2000) 12:597-603. doi:10.1016/S0952-7915(00)00148-5

29. Schaible UE, Winau F, Sieling PA, Fischer K, Collins HL, Hagens K, et al. Apoptosis facilitates antigen presentation to T lymphocytes through MHC-I and CD1 in tuberculosis. Nat Med (2003) 9:1039-46. doi:10.1038/nm906

30. Winau F, Weber S, Sad S, De Diego J, Hoops SL, Breiden B, et al. Apoptotic vesicles crossprime CD8 T cells and protect against tuberculosis. Immunity (2006) 24:105-17. doi:10.1016/j.immuni.2005.12.001

31. Herbst S, Schaible UE, Schneider BE. Interferon gamma activated macrophages kill mycobacteria by nitric oxide induced apoptosis. PLoS One (2011) 6:e19105. doi:10.1371/journal.pone.0019105

32. Corleis B, Korbel D, Wilson R, Bylund J, Chee R, Schaible UE. Escape of Mycobacterium tuberculosis from oxidative killing by neutrophils. Cell Microbiol (2012) 14:1109-21. doi:10.1111/j.1462-5822.2012.01783.x

33. Lai YM, Mohammed KA, Nasreen N, Baumuratov A, Bellew BF, Antony VB. Induction of cell cycle arrest and apoptosis by BCG infection in cultured human bronchial airway epithelial cells. Am J Physiol Lung Cell Mol Physiol (2007) 293:L393-401. doi:10.1152/ajplung.00392.2006

34. Wong KW, Jacobs WR Jr. Postprimary tuberculosis and macrophage necrosis: is there a big ConNECtion? MBio (2016) 7:e01589-15. doi:10.1128/ mBio.01589-15

35. Behar SM, Martin CJ, Booty MG, Nishimura T, Zhao X, Gan HX, et al. Apoptosis is an innate defense function of macrophages against Mycobacterium tuberculosis. Mucosal Immunol (2011) 4:279-87. doi:10.1038/ mi.2011.3

36. Aporta A, Arbues A, Aguilo JI, Monzon M, Badiola JJ, De Martino A, et al. Attenuated Mycobacterium tuberculosis $\mathrm{SO} 2$ vaccine candidate is unable to induce cell death. PLoS One (2012) 7:e45213. doi:10.1371/journal. pone. 0045213

37. Augenstreich J, Arbues A, Simeone R, Haanappel E, Wegener A, Sayes F, et al. ESX-1 and phthiocerol dimycocerosates of Mycobacterium tuberculosis act in concert to cause phagosomal rupture and host cell apoptosis. Cell Microbiol (2017) 19:e12726. doi:10.1111/cmi.12726

38. Simeone R, Bobard A, Lippmann J, Bitter W, Majlessi L, Brosch R, et al. Phagosomal rupture by Mycobacterium tuberculosis results in toxicity and host cell death. PLoS Pathog (2012) 8:e1002507. doi:10.1371/journal ppat.1002507

39. Repasy T, Lee J, Marino S, Martinez N, Kirschner DE, Hendricks G, et al. Intracellular bacillary burden reflects a burst size for Mycobacterium 
tuberculosis in vivo. PLoS Pathog (2013) 9:e1003190. doi:10.1371/journal. ppat. 1003190

40. Grode L, Seiler P, Baumann S, Hess J, Brinkmann V, Nasser Eddine A, et al. Increased vaccine efficacy against tuberculosis of recombinant Mycobacterium bovis bacille Calmette-Guerin mutants that secrete listeriolysin. J Clin Invest (2005) 115:2472-9. doi:10.1172/JCI24617

41. Scheffer SR, Nave H, Korangy F, Schlote K, Pabst R, Jaffee EM, et al. Apoptotic, but not necrotic, tumor cell vaccines induce a potent immune response in vivo. Int J Cancer (2003) 103:205-11. doi:10.1002/ijc.10777

42. Polyzoidis S, Tuazon J, Brazil L, Beaney R, Al-Sarraj ST, Doey L, et al. Active dendritic cell immunotherapy for glioblastoma: current status and challenges. Br J Neurosurg (2015) 29:197-205. doi:10.3109/02688697.2014. 994473

43. Garg AD, Vandenberk L, Koks C, Verschuere T, Boon L, Van Gool SW, et al. Dendritic cell vaccines based on immunogenic cell death elicit danger signals and $\mathrm{T}$ cell-driven rejection of high-grade glioma. Sci Transl Med (2016) 8:328ra27. doi:10.1126/scitranslmed.aae0105

44. Aaes TL, Kaczmarek A, Delvaeye T, De Craene B, De Koker S, Heyndrickx L, et al. Vaccination with necroptotic cancer cells induces efficient anti-tumor immunity. Cell Rep (2016) 15:274-87. doi:10.1016/j.celrep.2016.03.037

45. Wang J, Li B, Wu MX. Effective and lesion-free cutaneous influenza vaccination. Proc Natl Acad Sci U S A (2015) 112:5005-10. doi:10.1073/ pnas. 1500408112

46. Chen X, Kositratna G, Zhou C, Manstein D, Wu MX. Micro-fractional epidermal powder delivery for improved skin vaccination. J Control Release (2014) 192:310-6. doi:10.1016/j.jconrel.2014.08.006

47. Huang S, Cheng T-Y, Young DC, Layre E, Madigan CA, Shires J, et al. Discovery of deoxyceramides and diacylglycerols as CDIb scaffold lipids among diverse groove-blocking lipids of the human CD1 system. Proc Natl Acad Sci U S A (2011) 108:19335-40. doi:10.1073/pnas.1112969108

48. de Jong A. Activation of human T cells by CD1 and self-lipids. Immunol Rev (2015) 267:16-29. doi:10.1111/imr.12322

49. Moody DB, Zajonc DM, Wilson IA. Anatomy of CD1-lipid antigen complexes. Nat Rev Immunol (2005) 5:387-99. doi:10.1038/nri1605

50. Van Rhijn I, Moody DB. CD1 and mycobacterial lipids activate human T cells. Immunol Rev (2015) 264:138-53. doi:10.1111/imr.12253

51. Wu L, Van Kaer L. Natural killer T cells and autoimmune disease. Curr Mol Med (2009) 9:4-14. doi:10.2174/156652409787314534

52. Swann JB, Coquet JMC, Smyth MJ, Godfrey DI. CD1-Restricted T Cells and Tumor Immunity. Berlin, Heidelberg: Springer Berlin Heidelberg (2007).

53. Libero GD, Mori L. The T-cell response to lipid antigens of Mycobacterium tuberculosis. Front Immunol (2014) 5:1-1. doi:10.3389/fimmu.2014. 00219

54. Beckman EM, Porcelli SA, Morita CT, Behar SM, Furlong ST, Brenner MB. Recognition of a lipid antigen by CD1-restricted alpha beta+ T cells. Nature (1994) 372:691-4. doi:10.1038/372691a0

55. Gilleron M, Stenger S, Mazorra Z, Wittke F, Mariotti S, Bohmer G, et al. Diacylated sulfoglycolipids are novel mycobacterial antigens stimulating CD1-restricted T cells during infection with Mycobacterium tuberculosis. J Exp Med (2004) 199:649-59. doi:10.1084/jem.20031097

56. Sieling PA, Jullien D, Dahlem M, Tedder TF, Rea TH, Modlin RL, et al. CD1 expression by dendritic cells in human leprosy lesions: correlation with effective host immunity. J Immunol (1999) 162:1851-8.

57. Ulrichs T, Moody DB, Grant E, Kaufmann SHE, Porcelli SA. T-cell responses to CD1-presented lipid antigens in humans with Mycobacterium tuberculosis infection. Infect Immun (2003) 71:3076-87. doi:10.1128/ IAI.71.6.3076-3087.2003

58. Hiromatsu K, Dascher CC, Leclair KP, Sugita M, Furlong ST, Brenner MB, et al. Induction of CD1-restricted immune responses in guinea pigs by immunization with mycobacterial lipid antigens. J Immunol (2002) 169:330-9. doi:10.4049/jimmunol.169.1.330

59. Dascher CC, Hiromatsu K, Xiong X, Morehouse C, Watts G, Liu G, et al. Immunization with a mycobacterial lipid vaccine improves pulmonary pathology in the guinea pig model of tuberculosis. Int Immunol (2003) 15(8):915-25. doi:10.1093/intimm/dxg091

60. Larrouy-Maumus G, Layre E, Clark S, Prandi J, Rayner E, Lepore M, et al. Protective efficacy of a lipid antigen vaccine in a guinea pig model of tuberculosis. Vaccine (2017) 35:1395-402. doi:10.1016/j.vaccine.2017.01.079
61. Galli G, Nuti S, Tavarini S, Galli-Stampino L, De Lalla C, Casorati G, et al. CD1d-restricted help to B cells by human invariant natural killer T lymphocytes. J Exp Med (2003) 197:1051-7. doi:10.1084/jem.20021616

62. Leadbetter EA, Brigl M, Illarionov P, Cohen N, Luteran MC, Pillai S, et al. NK T cells provide lipid antigen-specific cognate help for B cells. Proc Natl Acad Sci U S A (2008) 105:8339-44. doi:10.1073/pnas.0801375105

63. Nguyen TK, Wieland W, Santema W, Hoeboer J, Van Eden W, Rutten V, et al. Immune response of cattle immunized with a conjugate of the glycolipid glucose monomycolate and protein. Vet Immunol Immunopathol (2011) 142:265-70. doi:10.1016/j.vetimm.2011.05.016

64. Di Nardo A, Wertz P, Giannetti A, Seidenari S. Ceramide and cholesterol composition of the skin of patients with atopic dermatitis. Acta Derm Venereol (1998) 78:27-30. doi:10.1080/00015559850135788

65. Motta S, Monti M, Sesana S, Caputo R, Carelli S, Ghidoni R. Ceramide composition of the psoriatic scale. Biochim Biophys Acta (1993) 1182:147-51. doi:10.1016/0925-4439(93)90135-N

66. Gadola SD, Zaccai NR, Harlos K, Shepherd D, Castro-Palomino JC, Ritter G, et al. Structure of human CD1b with bound ligands at $2.3 \AA$, a maze for alkyl chains. Nat Immunol (2002) 3:721-6. doi:10.1038/ni821

67. Hung J-T, Huang J-R, Yu AL. Tailored design of NKT-stimulatory glycolipids for polarization of immune responses. J Biomed Sci (2017) 24:22-22. doi:10.1186/s12929-017-0325-0

68. Miyamoto K, Miyake S, Yamamura T. A synthetic glycolipid prevents autoimmune encephalomyelitis by inducing TH2 bias of natural killer T cells. Nature (2001) 413:531-4. doi:10.1038/35097097

69. Chang Y-J, Huang J-R, Tsai Y-C, Hung J-T, Wu D, Fujio M, et al. Potent immune-modulating and anticancer effects of NKT cell stimulatory glycolipids. Proc Natl Acad Sci U S A (2007) 104:10299-304. doi:10.1073/pnas. 0703824104

70. Schmieg J, Yang G, Franck RW, Tsuji M. Superior protection against malaria and melanoma metastases by a C-glycoside analogue of the natural killer T cell ligand $\alpha$-galactosylceramide. J Exp Med (2003) 198:1631-41. doi:10.1084/jem.20031192

71. Carlin G, Djursäter R. Peroxidation of phospholipids promoted by myeloperoxidase. Free Radic Res Commun (1988) 4:251-7. doi:10.3109/ 10715768809055150

72. Claster S, Chiu DT, Quintanilha A, Lubin B. Neutrophils mediate lipid peroxidation in human red cells. Blood (1984) 64:1079-84.

73. Niki E. Lipid peroxidation: physiological levels and dual biological effects. Free Radic Biol Med (2009) 47:469-84. doi:10.1016/j.freeradbiomed.2009. 05.032

74. Agea E, Russano A, Bistoni O, Mannucci R, Nicoletti I, Corazzi L, et al. Human CD1-restricted T cell recognition of lipids from pollens. J Exp Med (2005) 202:295-308. doi:10.1084/jem.20050773

75. Gong J, Stenger S, Zack JA, Jones BE, Bristol GC, Modlin RL, et al. Isolation of Mycobacterium-reactive CD1-restricted T cells from patients with human immunodeficiency virus infection. J Clin Invest (1998) 101:383-9. doi:10.1172/JCI318

76. Gopal R, Lin Y, Obermajer N, Slight S, Nuthalapati N, Ahmed M, et al. IL-23-dependent IL-17 drives Th1-cell responses following Mycobacterium bovis BCG vaccination. Eur J Immunol (2012) 42:364-73. doi:10.1002/ eji.201141569

77. Pitt JM, Stavropoulos E, Redford PS, Beebe AM, Bancroft GJ, Young DB, et al. Blockade of IL-10 signaling during bacillus Calmette-Guerin vaccination enhances and sustains Th1, Th17, and innate lymphoid IFN-gamma and IL-17 responses and increases protection to Mycobacterium tuberculosis infection. J Immunol (2012) 189:4079-87. doi:10.4049/jimmunol.1201061

78. Abdalla AE, Li Q, Xie L, Xie J. Biology of IL-27 and its role in the host immunity against Mycobacterium tuberculosis. Int J Biol Sci (2015) 11:168-75. doi:10.7150/ijbs.10464

79. Moore KW, De Waal Malefyt R, Coffman RL, O'garra A. Interleukin-10 and the interleukin-10 receptor. Annu Rev Immunol (2001) 19:683-765. doi:10.1146/annurev.immunol.19.1.683

80. Belkaid Y, Hoffmann KF, Mendez S, Kamhawi S, Udey MC, Wynn TA, et al. The role of interleukin (IL)-10 in the persistence of Leishmania major in the skin after healing and the therapeutic potential of anti-IL-10 receptor antibody for sterile cure. J Exp Med (2001) 194:1497-506. doi:10.1084/ jem.194.10.1497 
81. Brooks DG, Trifilo MJ, Edelmann KH, Teyton L, Mc Gavern DB, Oldstone MB. Interleukin-10 determines viral clearance or persistence in vivo. Nat Med (2006) 12:1301-9. doi:10.1038/nm1492

82. Soares AP, Scriba TJ, Joseph S, Harbacheuski R, Murray RA, Gelderbloem SJ, et al. Bacillus Calmette-Guerin vaccination of human newborns induces $\mathrm{T}$ cells with complex cytokine and phenotypic profiles. JImmunol (2008) 180:3569-77. doi:10.4049/jimmunol.180.5.3569

83. Lalor MK, Smith SG, Floyd S, Gorak-Stolinska P, Weir RE, Blitz R, et al. Complex cytokine profiles induced by BCG vaccination in UK infants. Vaccine (2010) 28:1635-41. doi:10.1016/j.vaccine.2009.11.004

84. Akkoc T, Aydogan M, Yildiz A, Karakoc-Aydiner E, Eifan A, Keles S, et al. Neonatal BCG vaccination induces IL-10 production by CD4+ CD25+ T cells. Pediatr Allergy Immunol (2010) 21:1059-63. doi:10.1111/j.13993038.2010.01051.x

85. Zhang X, Majlessi L, Deriaud E, Leclerc C, Lo-Man R. Coactivation of Syk kinase and MyD88 adaptor protein pathways by bacteria promotes regulatory properties of neutrophils. Immunity (2009) 31:761-71. doi:10.1016/j. immuni.2009.09.016

86. Lindenstrom T, Woodworth J, Dietrich J, Aagaard C, Andersen P, Agger EM. Vaccine-induced th17 cells are maintained long-term postvaccination as a distinct and phenotypically stable memory subset. Infect Immun (2012) 80:3533-44. doi:10.1128/IAI.00550-12

87. Desel C, Werninghaus K, Ritter M, Jozefowski K, Wenzel J, Russkamp N, et al. The Mincle-activating adjuvant TDB induces MyD88-dependent Th1 and Th17 responses through IL-1R signaling. PLoS One (2013) 8:e53531. doi:10.1371/journal.pone.0053531

88. Schweneker K, Gorka O, Schweneker M, Poeck H, Tschopp J, Peschel C, et al. The mycobacterial cord factor adjuvant analogue trehalose-6,6'dibehenate (TDB) activates the Nlrp3 inflammasome. Immunobiology (2013) 218:664-73. doi:10.1016/j.imbio.2012.07.029

89. Decout A, Silva-Gomes S, Drocourt D, Barbe S, Andre I, Cueto FJ, et al. Rational design of adjuvants targeting the C-type lectin Mincle. Proc Natl Acad Sci U S A (2017) 114:2675-80. doi:10.1073/pnas.1612421114

90. Patin EC, Willcocks S, Orr S, Ward TH, Lang R, Schaible UE. Minclemediated anti-inflammatory IL-10 response counter-regulates IL-12 in vitro. Innate Immun (2016) 22(3):181-5. doi:10.1177/1753425916636671

91. Torrado E, Cooper AM. Cytokines in the balance of protection and pathology during mycobacterial infections. Adv Exp Med Biol (2013) 783:121-40. doi:10.1007/978-1-4614-6111-1_7

92. Alter G, Sekaly RP. Beyond adjuvants: antagonizing inflammation to enhance vaccine immunity. Vaccine (2015) 33(Suppl 2):B55-9. doi:10.1016/j. vaccine.2015.03.058

93. du Plessis N, Loebenberg L, Kriel M, Von Groote-Bidlingmaier F, Ribechini E, Loxton AG, et al. Increased frequency of myeloid-derived suppressor cells during active tuberculosis and after recent Mycobacterium tuberculosis infection suppresses T-cell function. Am J Respir Crit Care Med (2013) 188:724-32. doi:10.1164/rccm.201302-0249OC

94. Yang B, Wang X, Jiang J, Zhai F, Cheng X. Identification of CD244-expressing myeloid-derived suppressor cells in patients with active tuberculosis. Immunol Lett (2014) 158:66-72. doi:10.1016/j.imlet.2013.12.003

95. El Daker S, Sacchi A, Tempestilli M, Carducci C, Goletti D, Vanini V, et al. Granulocytic myeloid derived suppressor cells expansion during active pulmonary tuberculosis is associated with high nitric oxide plasma level. PLoS One (2015) 10:e0123772. doi:10.1371/journal.pone.0123772

96. Knaul JK, Jorg S, Oberbeck-Mueller D, Heinemann E, Scheuermann L, Brinkmann V, et al. Lung-residing myeloid-derived suppressors display dual functionality in murine pulmonary tuberculosis. Am J Respir Crit Care Med (2014) 190:1053-66. doi:10.1164/rccm.201405-0828OC

97. Sinha P, Okoro C, Foell D, Freeze HH, Ostrand-Rosenberg S, Srikrishna G. Proinflammatory S100 proteins regulate the accumulation of myeloid-derived suppressor cells. J Immunol (2008) 181:4666-75. doi:10.4049/jimmunol.181. 7.4666

98. Edgeworth J, Gorman M, Bennett R, Freemont P, Hogg N. Identification of p8,14 as a highly abundant heterodimeric calcium binding protein complex of myeloid cells. J Biol Chem (1991) 266:7706-13.

99. Xu D, Li Y, Li X, Wei LL, Pan Z, Jiang TT, et al. Serum protein S100A9, SOD3, and MMP9 as new diagnostic biomarkers for pulmonary tuberculosis by iTRAQ-coupled two-dimensional LC-MS/MS. Proteomics (2015) 15:58-67. doi:10.1002/pmic.201400366
100. Kang DD, Lin Y, Moreno JR, Randall TD, Khader SA. Profiling early lung immune responses in the mouse model of tuberculosis. PLoS One (2011) 6:e16161. doi:10.1371/journal.pone.0016161

101. Kraakman MJ, Lee MK, Al-Sharea A, Dragoljevic D, Barrett TJ, Montenont E, et al. Neutrophil-derived S100 calcium-binding proteins A8/A9 promote reticulated thrombocytosis and atherogenesis in diabetes. JClin Invest (2017) 127:2133-47. doi:10.1172/JCI92450

102. van den Bosch MH, Blom AB, Schelbergen RF, Koenders MI, Van De Loo FA, Van Den Berg WB, et al. Alarmin S100A9 induces proinflammatory and catabolic effects predominantly in the M1 macrophages of human osteoarthritic synovium. J Rheumatol (2016) 43:1874-84. doi:10.3899/jrheum. 160270

103. Schelbergen RF, Geven EJ, Van Den Bosch MH, Eriksson H, Leanderson T, Vogl T, et al. Prophylactic treatment with S100A9 inhibitor paquinimod reduces pathology in experimental collagenase-induced osteoarthritis. Ann Rheum Dis (2015) 74:2254-8. doi:10.1136/annrheumdis-2014-206517

104. Deronic A, Helmersson S, Leanderson T, Ivars F. The quinoline-3-carboxamide paquinimod (ABR-215757) reduces leukocyte recruitment during sterile inflammation: leukocyte- and context-specific effects. Int Immunopharmacol (2014) 18:290-7. doi:10.1016/j.intimp.2013.12.008

105. Stenstrom M, Nyhlen HC, Torngren M, Liberg D, Sparre B, Tuvesson H, et al. Paquinimod reduces skin fibrosis in tight skin 1 mice, an experimental model of systemic sclerosis. J Dermatol Sci (2016) 83:52-9. doi:10.1016/j. jdermsci.2016.04.006

106. Chiacchio T, Casetti R, Butera O, Vanini V, Carrara S, Girardi E, et al. Characterization of regulatory $\mathrm{T}$ cells identified as CD4(+)CD25(high) CD39(+) in patients with active tuberculosis. Clin Exp Immunol (2009) 156: 463-70. doi:10.1111/j.1365-2249.2009.03908.x

107. Sharma PK, Saha PK, Singh A, Sharma SK, Ghosh B, Mitra DK. FoxP3+ regulatory $\mathrm{T}$ cells suppress effector T-cell function at pathologic site in miliary tuberculosis. Am J Respir Crit Care Med (2009) 179:1061-70. doi:10.1164/ rccm.200804-529OC

108. Pang H, Yu Q, Guo B, Jiang Y, Wan L, Li J, et al. Frequency of regulatory T-cells in the peripheral blood of patients with pulmonary tuberculosis from shanxi province, china. PLoS One (2013) 8:e65496. doi:10.1371/journal. pone.0065496

109. Shafiani S, Tucker-Heard G, Kariyone A, Takatsu K, Urdahl KB. Pathogenspecific regulatory $\mathrm{T}$ cells delay the arrival of effector $\mathrm{T}$ cells in the lung during early tuberculosis. JExp Med (2010) 207:1409-20. doi:10.1084/ jem.20091885

110. Chen CY, Huang D, Yao S, Halliday L, Zeng G, Wang RC, et al. IL-2 simultaneously expands Foxp3+ $\mathrm{T}$ regulatory and $\mathrm{T}$ effector cells and confers resistance to severe tuberculosis (TB): implicative Treg-T effector cooperation in immunity to TB. J Immunol (2012) 188:4278-88. doi:10.4049/ jimmunol.1101291

111. Bhattacharya D, Dwivedi VP, Maiga M, Maiga M, Van Kaer L, Bishai WR, et al. Small molecule-directed immunotherapy against recurrent infection by Mycobacterium tuberculosis. J Biol Chem (2014) 289:16508-15. doi:10.1074/ jbc.M114.558098

112. Bhattacharya D, Dwivedi VP, Kumar S, Reddy MC, Van KAER L, Moodley P, et al. Simultaneous inhibition of $\mathrm{T}$ helper 2 and $\mathrm{T}$ regulatory cell differentiation by small molecules enhances Bacillus Calmette-Guerin vaccine efficacy against tuberculosis. J Biol Chem (2014) 289:33404-11. doi:10.1074/jbc.M114.600452

113. Boer MC, Joosten SA, Ottenhoff TH. Regulatory T-cells at the interface between human host and pathogens in infectious diseases and vaccination. Front Immunol (2015) 6:217. doi:10.3389/fimmu.2015.00217

114. Dhiman R, Periasamy S, Barnes PF, Jaiswal AG, Paidipally P, Barnes AB, et al. NK1.1+ cells and IL-22 regulate vaccine-induced protective immunity against challenge with Mycobacterium tuberculosis. JImmunol (2012) 189:897-905. doi:10.4049/jimmunol.1102833

115. Luo Y, Jiang W, Da Z, Wang B, Hu L, Zhang Y, et al. Subunit vaccine candidate AMM down-regulated the regulatory $\mathrm{T}$ cells and enhanced the protective immunity of BCG on a suitable schedule. Scand J Immunol (2012) 75:293-300. doi:10.1111/j.1365-3083.2011.02666.x

116. Jaron B, Maranghi E, Leclerc C, Majlessi L. Effect of attenuation of Treg during BCG immunization on anti-mycobacterial Th1 responses and protection against Mycobacterium tuberculosis. PLoS One (2008) 3:e2833. doi:10.1371/ journal.pone. 0002833 
117. Jasenosky LD, Scriba TJ, Hanekom WA, Goldfeld AE. T cells and adaptive immunity to Mycobacterium tuberculosis in humans. Immunol Rev (2015) 264:74-87. doi:10.1111/imr.12274

118. Urdahl KB, Shafiani S, Ernst JD. Initiation and regulation of T-cell responses in tuberculosis. Mucosal Immunol (2011) 4:288-93. doi:10.1038/mi.2011.10

119. Lewinsohn DA, Lewinsohn DM, Scriba TJ. Polyfunctional CD4+ T cells as targets for tuberculosis vaccination. Front Immunol (2017) 8:1262. doi:10.3389/fimmu.2017.01262

120. Vivier E, Raulet DH, Moretta A, Caligiuri MA, Zitvogel L, Lanier LL, et al. Innate or adaptive immunity? The example of natural killer cells. Science (2011) 331:44-9. doi:10.1126/science.1198687

121. Paust S, von Andrian UH. Natural killer cell memory. Nat Immunol (2011) 12:500-8. doi:10.1038/ni.2032

122. Cerwenka A, Lanier LL. Natural killer cell memory in infection, inflammation and cancer. Nat Rev Immunol (2016) 16:112-23. doi:10.1038/nri.2015.9

123. O'Sullivan TE, Sun JC, Lanier LL. Natural killer cell memory. Immunity (2015) 43:634-45. doi:10.1016/j.immuni.2015.09.013

124. Choreno Parra JA, Martinez Zuniga N, Jimenez Zamudio LA, Jimenez Alvarez LA, Salinas Lara C, Zuniga J. Memory of natural killer cells: a new chance against Mycobacterium tuberculosis? Front Immunol (2017) 8:967. doi:10.3389/fimmu.2017.00967

125. Schierloh P, Yokobori N, Aleman M, Landoni V, Geffner L, Musella RM, et al. Mycobacterium tuberculosis-induced gamma interferon production by natural killer cells requires cross talk with antigen-presenting cells involving toll-like receptors 2 and 4 and the mannose receptor in tuberculous pleurisy. Infect Immun (2007) 75:5325-37. doi:10.1128/IAI.00381-07

126. Fu X, Yu S, Yang B, Lao S, Li B, Wu C. Memory-like antigen-specific human NK cells from TB pleural fluids produced IL-22 in response to IL-15 or Mycobacterium tuberculosis antigens. PLoS One (2016) 11:e0151721. doi:10.1371/journal.pone.0151721

127. Venkatasubramanian S, Cheekatla S, Paidipally P, Tripathi D, Welch E, Tvinnereim AR, et al. IL-21-dependent expansion of memory-like NK cells enhances protective immune responses against Mycobacterium tuberculosis. Mucosal Immunol (2017) 10:1031-42. doi:10.1038/mi. 2016.105

128. Junqueira-Kipnis AP, Kipnis A, Jamieson A, Juarrero MG, Diefenbach A, Raulet DH, et al. NK cells respond to pulmonary infection with Mycobacterium tuberculosis, but play a minimal role in protection. J Immunol (2003) 171:6039-45. doi:10.4049/jimmunol.171.11.6039

129. Esin S, Batoni G. Natural killer cells: a coherent model for their functional role in Mycobacterium tuberculosis infection. J Innate Immun (2015) 7:11-24. doi:10.1159/000363321

130. Suliman S, Geldenhuys H, Johnson JL, Hughes JE, Smit E, Murphy M, et al. Bacillus Calmette-Guerin (BCG) revaccination of adults with latent Mycobacterium tuberculosis infection induces long-lived BCG-reactive NK cell responses. J Immunol (2016) 197:1100-10. doi:10.4049/jimmunol. 1501996

131. Kleinnijenhuis J, Quintin J, Preijers F, Joosten LA, Jacobs C, Xavier RJ, et al. BCG-induced trained immunity in NK cells: role for non-specific protection to infection. Clin Immunol (2014) 155:213-9. doi:10.1016/j.clim. 2014.10.005

132. Netea MG, Quintin J, Van Der Meer JW. Trained immunity: a memory for innate host defense. Cell Host Microbe (2011) 9:355-61. doi:10.1016/j. chom.2011.04.006

133. Netea MG, van Crevel R. BCG-induced protection: effects on innate immune memory. Semin Immunol (2014) 26:512-7. doi:10.1016/j.smim. 2014.09.006

134. Blok BA, Arts RJ, Van Crevel R, Benn CS, Netea MG. Trained innate immunity as underlying mechanism for the long-term, nonspecific effects of vaccines. J Leukoc Biol (2015) 98:347-56. doi:10.1189/jlb.5RI0315-096R

135. Arts RJW, Carvalho A, La Rocca C, Palma C, Rodrigues F, Silvestre R, et al. Immunometabolic pathways in BCG-induced trained immunity. Cell Rep (2016) 17:2562-71. doi:10.1016/j.celrep.2016.11.011
136. Kleinnijenhuis J, Quintin J, Preijers F, Joosten LA, Ifrim DC, Saeed S, et al. Bacille Calmette-Guerin induces NOD2-dependent nonspecific protection from reinfection via epigenetic reprogramming of monocytes. Proc Natl Acad Sci U S A (2012) 109:17537-42. doi:10.1073/pnas.1202870109

137. Kagina BM, Abel B, Scriba TJ, Hughes EJ, Keyser A, Soares A, et al. Specific $\mathrm{T}$ cell frequency and cytokine expression profile do not correlate with protection against tuberculosis after bacillus Calmette-Guerin vaccination of newborns. Am J Respir Crit Care Med (2010) 182:1073-9. doi:10.1164/ rccm.201003-0334OC

138. Fong L, Kwek SS, O’Brien S, Kavanagh B, McNeel DG, Weinberg V, et al. Potentiating endogenous antitumor immunity to prostate cancer through combination immunotherapy with CTLA4 blockade and GM-CSF. Cancer Res (2009) 69:609-15. doi:10.1158/0008-5472.CAN-08-3529

139. Hirano F, Kaneko K, Tamura H, Dong H, Wang S, Ichikawa M, et al. Blockade of B7-H1 and PD-1 by monoclonal antibodies potentiates cancer therapeutic immunity. Cancer Res (2005) 65:1089-96.

140. Mukherjee P, Basu GD, Tinder TL, Subramani DB, Bradley JM, Arefayene M, et al. Progression of pancreatic adenocarcinoma is significantly impeded with a combination of vaccine and COX-2 inhibition. J Immunol (2009) 182:216-24. doi:10.4049/jimmunol.182.1.216

141. Basu GD, Tinder TL, Bradley JM, Tu T, Hattrup CL, Pockaj BA, et al. Cyclooxygenase-2 inhibitor enhances the efficacy of a breast cancer vaccine: role of IDO. J Immunol (2006) 177:2391-402. doi:10.4049/jimmunol.177. 4.2391

142. Inoue J, Aramaki Y. Cyclooxygenase-2 inhibition promotes enhancement of antitumor responses by transcutaneous vaccination with cytosinephosphate-guanosine-oligodeoxynucleotides and model tumor antigen. J Invest Dermatol (2007) 127:614-21. doi:10.1038/sj.jid.5700656

143. Pettersen FO, Torheim EA, Dahm AE, Aaberge IS, Lind A, Holm M, et al. An exploratory trial of cyclooxygenase type 2 inhibitor in HIV-1 infection: downregulated immune activation and improved $\mathrm{T}$ cell-dependent vaccine responses. J Virol (2011) 85:6557-66. doi:10.1128/JVI.00073-11

144. Taus F, Santucci MB, Greco E, Morandi M, Palucci I, Mariotti S, et al. Monosodium urate crystals promote innate anti-mycobacterial immunity and improve BCG efficacy as a vaccine against tuberculosis. PLoS One (2015) 10:e0127279. doi:10.1371/journal.pone.0127279

145. Jagannath C, Lindsey DR, Dhandayuthapani S, Xu Y, Hunter RL Jr, Eissa NT. Autophagy enhances the efficacy of BCG vaccine by increasing peptide presentation in mouse dendritic cells. Nat Med (2009) 15:267-76. doi:10.1038/nm.1928

146. Cruz A, Fraga AG, Fountain JJ, Rangel-Moreno J, Torrado E, Saraiva M, et al. Pathological role of interleukin 17 in mice subjected to repeated BCG vaccination after infection with Mycobacterium tuberculosis. JExp Med (2010) 207:1609-16. doi:10.1084/jem.20100265

147. Nambiar JK, Ryan AA, Kong CU, Britton WJ, Triccas JA. Modulation of pulmonary DC function by vaccine-encoded GM-CSF enhances protective immunity against Mycobacterium tuberculosis infection. Eur J Immunol (2010) 40:153-61. doi:10.1002/eji.200939665

148. O’Donnell MA, Aldovini A, Duda RB, Yang H, Szilvasi A, Young RA, et al. Recombinant Mycobacterium bovis BCG secreting functional interleukin-2 enhances gamma interferon production by splenocytes. Infect Immun (1994) 62:2508-14.

Conflict of Interest Statement: The authors declare that the research was conducted in the absence of any commercial or financial relationships that could be construed as a potential conflict of interest.

Copyright (๑) 2017 Schaible, Linnemann, Redinger, Patin and Dallenga. This is an open-access article distributed under the terms of the Creative Commons Attribution License (CC BY). The use, distribution or reproduction in other forums is permitted, provided the original author $(s)$ or licensor are credited and that the original publication in this journal is cited, in accordance with accepted academic practice. No use, distribution or reproduction is permitted which does not comply with these terms. 